\title{
Energy in buildings: Efficiency, renewables and storage
}

\author{
Matthias M. $\operatorname{Koebel}(*)$ \\ Swiss Federal Laboratories for Materials Science and Technology, Empa \\ Ueberlandstrasse 129, CH-8600, Duebendorf, Switzerland
}

\begin{abstract}
Summary. - This lecture summary provides a short but comprehensive overview on the "energy and buildings" topic. Buildings account for roughly $40 \%$ of the global energy demands. Thus, an increased adoption of existing and upcoming materials and solutions for the building sector represents an enormous potential to reduce building related energy demands and greenhouse gas emissions. The central question is how the building envelope (insulation, fenestration, construction style, solar control) affects building energy demands. Compared to conventional insulation materials, superinsulation materials such as vacuum insulation panels and silica aerogel achieve the same thermal performance with significantly thinner insulation layers. With low-emissivity coatings and appropriate filler gasses, double and triple glazing reduce thermal losses by up to an order of magnitude compared to old single pane windows, while vacuum insulation and aerogel filled glazing could reduce these even further. Electrochromic and other switchable glazing solutions maximize solar gains during wintertime and minimize illumination demands whilst avoiding overheating in summer. Upon integration of renewable energy systems into the building energy supply, buildings can become both producers and consumers of energy. Combined with dynamic user behavior, temporal variations in the production of renewable energy require appropriate storage solutions, both thermal and electrical, and the integration of buildings into smart grids and energy district networks. The combination of these measures allows a reduction of the existing building stock by roughly a factor of three - a promising, but cost intensive way, to prepare our buildings for the energy turnaround.
\end{abstract}

$\left(^{*}\right)$ Email: matthias.koebel@empa.ch, www.empa.ch 


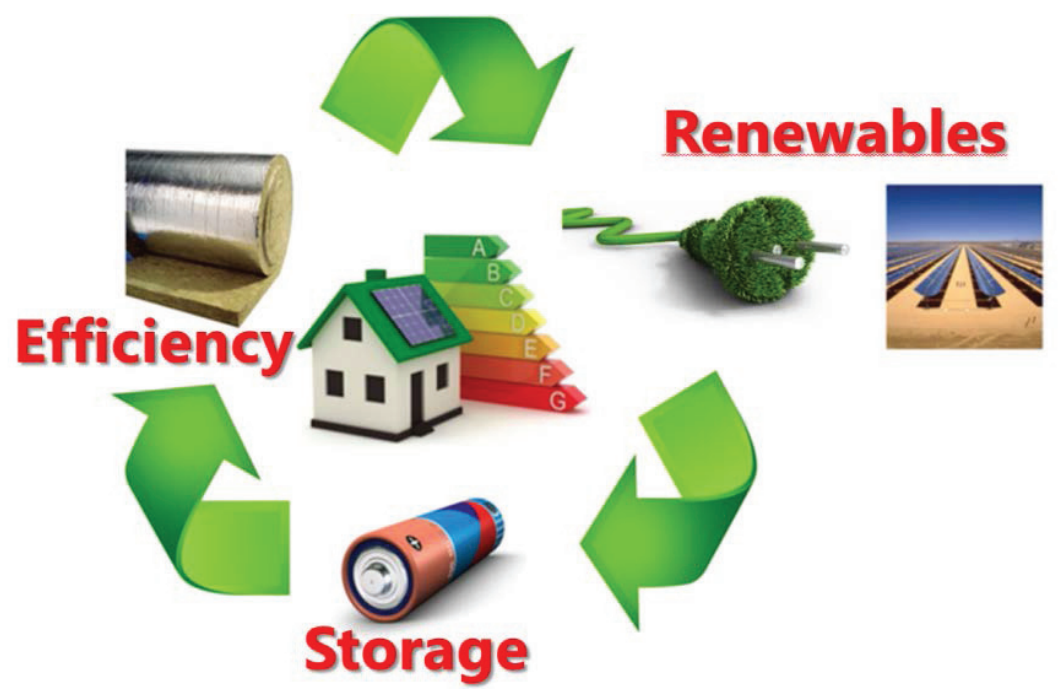

Fig. 1. - Modern energy-efficient buildings require a balanced interplay between an efficient envelope (insulation), the on-site generation of renewables and energy storage in a suitable form.

\section{1. - Overview and context}

Our built environment is the largest energy consuming sector - roughly $40 \%$ of the world's energy demand is attributed to heating, ventilation and air conditioning (HVAC) of buildings [1]. Modern buildings perform substantially better because of tightening building codes and regulations regarding their energy performance, nevertheless the majority of existing buildings are older and thus in dire need for refurbishment. The three key steps to a low-energy or plus-energy building are i) an efficient envelope which minimizes thermal losses and maximizes solar gains in winter while excluding them in the summer, ii) harvesting of renewable energies at the building itself (e.g. through photovoltaics) sufficient to cover a large fraction of the buildings annual consumption and iii) putting in place suitable energy storage systems (thermal or electrical). Furthermore, thermal and electrical storage systems can be shared between multiple houses within a district in order to manage and balance the dissimilar time-dependent production/demand profiles of individual homes (e.g. through smart IOT solutions). Such energy district network concepts allow significant energy savings at district and city level operation and reduce peak loads on the energy infrastructure (fig. 1).

\section{2. - Thermal insulation and superinsulation materials}

To address the first problem, namely improving the quality of the building envelope to reduce thermal losses, let us consider the installation of suitable insulation materials. Insulation performance of a material is described in terms of the thermal conductivity $\lambda$ with units of $\mathrm{W} /(\mathrm{m} \mathrm{K})$. Typical conventional materials include foamed plastics 
(Polystyrene foam, $\lambda \sim 0.03 \mathrm{~W} /(\mathrm{m} \mathrm{K})$, PU/PUR/PIR foam, $\lambda \sim 0.024 \mathrm{~W} /(\mathrm{m} \mathrm{K})$ ), mineral and glass wool $(\lambda \sim 0.033 \mathrm{~W} /(\mathrm{m} \mathrm{K}))$ and a number of other less commonly used materials (cellulose fibers, natural materials, melamine foam etc.), see table I. All those materials are highly optimized and offer good value for money but are close to their respective product life cycle and can no longer keep up with ever increasing demands of European building codes.

Architects and planners are generally not thrilled with current building policy which essentially calls for ever increasing thicknesses of insulation layers. But are there highperformance alternatives to existing insulation materials which allow slimmer construction? Sure there are. To understand what they are and how they work, we need to first understand the limitations of existing insulation materials. In a thermal insulator, air is responsible for the majority of total heat transport. In a porous insulation material with submillimeter pore sizes, the total thermal conductivity $\lambda_{\text {tot }}$ is the sum of gas, solid and radiative conductivities, respectively according to

$$
\lambda_{\text {tot }}(T, p)=\lambda_{\mathrm{g}}(T, p)+\lambda_{\mathrm{s}}(T)+\lambda_{\mathrm{r}}(T) .
$$

Both solid and radiative conductivity are more or less independent of pressure. Note that for the discussion of building insulation, people generally refer to ambient temperature and pressure conditions, although many industry standard measurements are done at $10^{\circ} \mathrm{C}$. For still ambient air, the gas conductivity, $\lambda_{\mathrm{g}, \infty}$ is roughly $0.026 \mathrm{~W} /(\mathrm{m} \mathrm{K})$ and is clearly the dominant form of heat transport in normal insulation materials by comparison with the above insulation material $\lambda$ values. This shows that skeletal and radiative transport in these materials typically adds up to $3-10 \mathrm{~mW} /(\mathrm{m} \mathrm{K})$ depending on the structure. It also illustrates the intrinsic difficulty for further reducing gas transport with ambient air as a filler gas. Polyisocyanate foams such as PU/PUR/PIR owe their high performance to a blowing gas mixture with lower gas conductivity (typically mixtures of $\mathrm{CO}_{2}, \lambda_{\mathrm{g}}=0.015 \mathrm{~W} /(\mathrm{m} \mathrm{K})$ and isopentane, $\left.\lambda_{\mathrm{g}}=0.0144 \mathrm{~W} /(\mathrm{m} \mathrm{K})\right)$. To further decrease lambda values, halogenated (e.g. fluoro-chloro)-hydrocarbons have been used in the past, but these have been banned due to their ozone layer harming potential. Yet there are alternatives to achieve a further reduction of the gas conductivity. A further reduction of the gas conductivity into the so-called superinsulating regime (recent definition: $\lambda<$ $0.02 \mathrm{~W} /(\mathrm{m} \mathrm{K})[2])$ without the use of harmful or trace noble gas fillers ( $\mathrm{Kr}, \mathrm{Xe})$ can also be achieved by other means:

$$
\begin{aligned}
\lambda_{\mathrm{g}} & =\lambda_{\mathrm{g}, \infty} \frac{1}{(1+2 \beta K n)}, \\
K n & =\frac{l}{\Phi} .
\end{aligned}
$$

The gas conductivity for a gas where the predominant mode of energy transport is collisions between gas molecules is referred to as the so-called free gas conductivity $\lambda_{\mathrm{g}, \infty}$. Equation (2) shows a correction term to the free gas conductivity which is inversely proportional to the Knudsen number $K n$ [3]. $\beta$ is a gas-dependent constant which is about 
TABLE I. - Overview of standard building envelope technologies and solutions, particularly for thermal insulation and for windows.

\begin{tabular}{|c|c|c|c|c|c|c|c|}
\hline & $\begin{array}{c}\text { Thermal } \\
\text { conductivity } \\
{[\mathrm{W} /(\mathrm{m} \mathrm{K})]}\end{array}$ & Combustible & $\begin{array}{c}\text { Material } \\
\text { cost } \\
{\left[\mathrm{EUR} / \mathrm{m}^{3}\right]}\end{array}$ & $\begin{array}{c}U \text {-value } \\
{\left[\mathrm{W} /\left(\mathrm{m}^{2} \mathrm{~K}\right)\right]}\end{array}$ & $\begin{array}{c}g \text {-value } \\
{[]}\end{array}$ & $\begin{array}{c}\text { Glazing } \\
\text { cost } \\
\mathrm{EUR} / \mathrm{m}^{2}\end{array}$ & \begin{tabular}{|c|} 
Service \\
life \\
{$[\mathrm{a}]$} \\
\end{tabular} \\
\hline $\begin{array}{l}\text { Conventional } \\
\text { insulation }\end{array}$ & & & & & & & \\
\hline Mineral wool & $0.032-0.045$ & no & 120 & & & & $>50 \mathrm{a}$ \\
\hline Glass wool & $0.030-0.040$ & no & 120 & & & & $>50 \mathrm{a}$ \\
\hline $\begin{array}{l}\text { Polystyrene } \\
\text { foam }\end{array}$ & $0.029-0.037$ & yes & 70 & & & & $>50 \mathrm{a}$ \\
\hline $\begin{array}{l}\text { PUR/PIR } \\
\text { foam }\end{array}$ & $0.021-0.025$ & yes & 160 & & & & $>30 \mathrm{a}$ \\
\hline Superinsulation & & & & & & & \\
\hline $\begin{array}{l}\text { Silica aerogel } \\
\text { blanket }\end{array}$ & $0.015-0.018$ & no & 3000 & & & & $>50 a$ \\
\hline $\begin{array}{l}\text { Silica aerogel } \\
\text { granulate }\end{array}$ & $0.018-0.022$ & no & 2800 & & & & $>50 a$ \\
\hline $\begin{array}{l}\text { Silica aerogel } \\
\text { powder }\end{array}$ & $0.020-0.025$ & no & 2500 & & & & $>50 \mathrm{a}$ \\
\hline $\begin{array}{l}\text { Fumed silica } \\
\text { core VIP }\end{array}$ & 0.007 & no & 4500 & & & & $>30 \mathrm{a}$ \\
\hline $\begin{array}{l}\text { Window } \\
\text { technology }\end{array}$ & & & & & & & \\
\hline $\begin{array}{l}\text { Standard double } \\
\text { glazing } \\
\text { (soft low-e, } \\
\text { Ar fill) }\end{array}$ & & & & $1.0-1.1$ & $0.6-0.8$ & $45-60$ & $>25 \mathrm{a}$ \\
\hline $\begin{array}{l}\text { Standard triple } \\
\text { glazing } \\
\text { (soft low-e, } \\
\text { Ar fill) } \\
\text { Vacuum } \\
\text { glazing } \\
\text { (soft low-e, } \\
\text { high vacuuml) }\end{array}$ & & & & $0.65-0.75$ & $0.6-0.8$ & $\begin{array}{c}65-80 \\
120-250\end{array}$ & $>25 \mathrm{a}$ \\
\hline
\end{tabular}

1.6 for air. The Knudsen number is defined as the ratio of mean free path of the filler gas $l$ to the critical container length $\Phi$ (eq. (2)). For insulation materials, the latter can be approximated by the pore size. At ambient pressure, the mean free path of air molecules is in the $70-100 \mathrm{~nm}$ range. For typical insulation materials with pore sizes in the hundreds of microns, the Knudsen number is then on the order of $10^{-3}$ which makes the correction 
term to the free gas conductivity become very close to 1 . However if we were remove the air from an insulator by partial evacuation, the correction term would strongly differ from unity. At 1 mbar vacuum, the mean free path of air is also on the order of 100 microns which would yield a Knudsen number of 1 . In this case, one would calculate a gas conductivity of roughly $0.026 \mathrm{~W} /(\mathrm{m} \mathrm{K}) \times 1 / 4.2$ which is approximately $6 \mathrm{~mW} /(\mathrm{m} \mathrm{K})$ or roughly $20 \mathrm{~mW} /(\mathrm{m} \mathrm{K})$ lower than that of free air - a massive reduction. The corresponding product is a vacuum insulation panel (VIP), commercially available in the form of a porous core (fumed silica is the material of choice for building applications) and a high-tech metallized multilayer laminate foil to ensure gas tightness [4]. Such VIPs attain declaration values of $0.006-0.007 \mathrm{~W} /(\mathrm{m} \mathrm{K})$ at vacuum levels in the single digit mbar range and service life numbers up to 30 years. However, they are subject to aging, particularly at temperatures $>50{ }^{\circ} \mathrm{C}$ and high humidity and of course to mechanical damage (piercing of the foil) which renders them less attractive for building insulation applications.

A second way to significantly lower the gas conductivity is to reduce the pore size of the material to the nanoscale size range. Such superinsulating materials are aerogels with typical average pore sizes on the order of $40 \mathrm{~nm}$. Using again eq. (2) and the Knudsen number for ambient air $(40 \mathrm{~nm} / 70 \mathrm{~nm} \sim 0.57)$, the gas conductivity is reduced from 26 to $9.2 \mathrm{~mW} /(\mathrm{m} \mathrm{K})$. Aerogels are a class of highly porous materials consisting of a fine pore structure with a majority of pores in the mesopore range $(2-50 \mathrm{~nm})$. They exist in many different compositions, chemistries (inorganic, organic, metallic) and building block morphologies (single phase, hybrids, hierarchical) [5]. The most common type of aerogels are based on silica and the only commercial materials today (see fig. 2). Monolithic products are difficult and costly to manufacture and have not yet been commercialized although BASF is currently working on a polyurea-based aerogel monolith product which could become commercially available as early as 2019 [6]. Blanket and granulate products are available from leading manufacturers Aspen Aerogels and Cabot. For building applications, these semifinished products must be adapted to solutions and products which are commensurate with the construction process. Aspen blankets are glued together and cut to create insulation boards such as Heck Aero which then finds application in aerogelbased ETICS solutions. Wet applied insulating render [7] and concrete [8] products are based on aerogel granulate.

Since the turn of the millennium, many demonstration objects and solutions have been realized using superinsulating materials and components. However these are primarily niche applications such as flat roof balcony insulation, window reveals, roller blind shutter box insulation and alcoves. Despite the high performance and added value of these solutions, price is still the key inhibitor for rapid market uptake, particularly for aerogel materials. If we want to achieve broader market uptake of aerogel-based solutions, novel production concepts need to be found and implemented industrially.

Current pricing of semi-finished aerogel products (granulate and blankets) is between 2500 and $3000 \mathrm{EUR} / \mathrm{m}^{3}$, however, the cost for the installed solution for the end user is roughly twice that. At current pricing level, the additional benefit of an aerogel solution is annulled by the high pricing leading to poor market acceptance and effectively condemning aerogels to niche markets in the B\&C industry. 


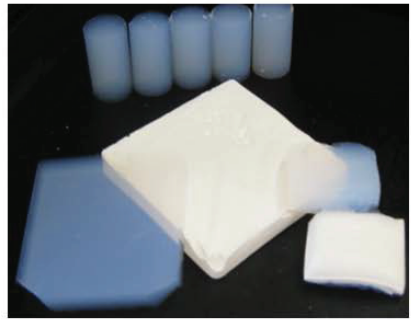

Monolithic aerogels $\lambda \approx 13 \mathrm{~mW} /(\mathrm{m} \cdot \mathrm{K})$

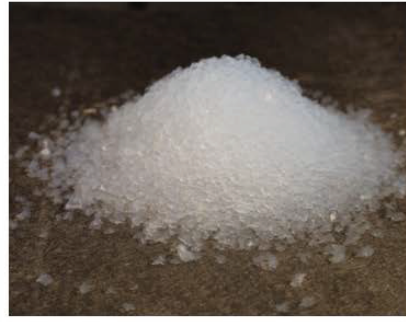

Granulate (packed bed)

$\lambda \approx 19 \mathrm{~mW} /(\mathrm{m} \cdot \mathrm{K})$

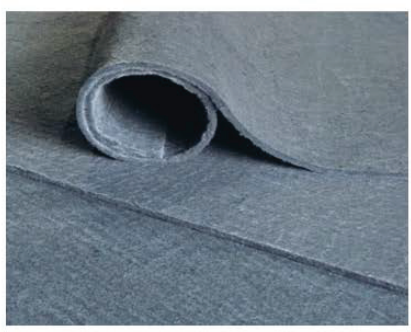

Aerogel blankets

$\lambda \approx 16 \mathrm{~mW} /(\mathrm{m} \cdot \mathrm{K})$

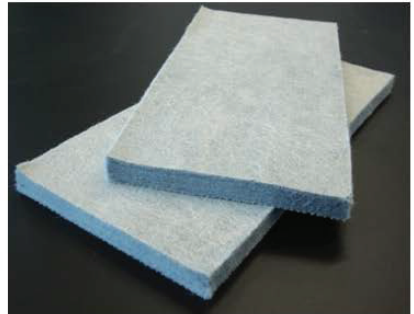

Insulation boards $\lambda \approx 17 \mathrm{~mW} /(\mathrm{m} \cdot \mathrm{K})$

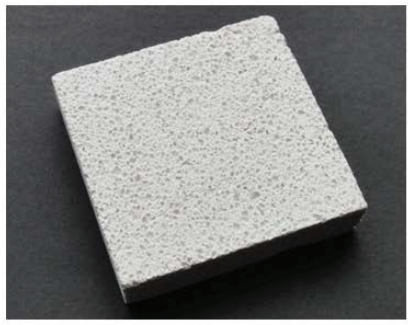

Paste-like (e.g. render) $\lambda \approx 28 \mathrm{~mW} /(\mathrm{m} \cdot \mathrm{K})$

Fig. 2. - Aerogel superinsulation materials offer promising technological solutions for building retrofit and new construction in urban aereas.

Experts believe that prices must be roughly cut in half to reach a more significant market penetration of superinsulating solutions in the built environment. For aerogels this means raw materials and installed product cost of roughly EUR $1500 / \mathrm{m}^{3}$ and 2500 $3000 \mathrm{EUR} / \mathrm{m}^{3}$, respectively. In order to reach these ambitions targets, new industrial processes must be developed that allow faster and more economical production of aerogels allowing for further price reductions through economy of scale. In parallel, insulation system providers and aerogel expert groups need to work together to develop new solutions which are easier to install and more user-friendly. Last but not least, innovative products and solutions must be made visible to the public in the form of lighthouse projects ideally supported by prominent media coverage in order to increase awareness. In this way, superinsulating materials can develop into a valuable industry for applications in retrofitting and urban construction.

\section{3. - Windows and glazing technology}

The second central pillar of building envelopes are the transparent part, namely glazing. In Europe, current glazing standards feature noble gas filled double and triple glazing with low-emissivity (low-E) coatings reaching typical center of glazing $U$-values of 1 and $0.65 \mathrm{~W} /\left(\mathrm{m}^{2} \mathrm{~K}\right)$, respectively (see table $\left.\mathrm{I}\right)$. This may seem rather high in comparison 
with new envelope insulation standard which are on the order of $0.2-0.3 \mathrm{~W} /\left(\mathrm{m}^{2} \mathrm{~K}\right)$, however windows generate significant solar gains also during winter months which normally outweigh thermal losses. Next generation technologies in the glazing industry are vacuum and multichamber glazing. A vacuum insulation glazing (VIG) is a double glazing unit with a high vacuum in between which completely eliminates gas conduction [9]. To prevent the two panes from touching under the load of the atmospheric pressure (10 tons $/ \mathrm{m}^{2}$ !), an array of thin spacers - so-called pillars - maintains the vacuum gap which is typically $0.2-0.7 \mathrm{~mm}$ thin. Theoretically, good vacuum glazing can achieve center of glazing $\mathrm{U}$ values as low as $0.3 \mathrm{~W} /\left(\mathrm{m}^{2} \mathrm{~K}\right)$ whit a total glazing thickness of less than $1 \mathrm{~cm}$. However the edge seal of VIGs is still a challenge to commercialize industrially and existing products today feature higher $U$-values which partly mitigates the problem of mechanical strains under thermal loads which is critical for the system's service life. Modern low- $U$-value alternatives to VIG currently under development are multichamber glazings ( $>4$ chambers) with either thin glass $(<1.5 \mathrm{~mm})$ or flexible, transparent polymer foils as separators. Such systems can achieve $U$-values as low as $0.3 \mathrm{~W} /\left(\mathrm{m}^{2} \mathrm{~K}\right)$ with weight comparable to a conventional triple glazing.

Aside from reducing thermal losses, modern window/glazing concepts also target the development of solar control technologies. Overheating during the hot summer months often represents a serious issue which typically leads to significantly increased cooling loads and thus electrical energy demand. In a standard double/triple glazing, the total solar energy transmittance or $g$-value is between 0.5 and 0.75 meaning that these windows transmit between 50 and $75 \%$ of incident total solar energy. Static (constant $g$-value) solar control measures include solar protection glass which contains selective coatings that only transmit the visible part of the optical spectrum but reflect infrared radiation and tinted glass. Dynamic solutions respond to an external stimulus and are promising alternatives to mechanical blinds which are maintenance intensive and sensitive to storm/hail damage. Modern concepts of such dynamic solutions include micro-vane blinds such as the MicroShade product by the Danish company Photosolar which features angular dependent $g$-values (low solar gains in summer, high solar gains in winter). Other solutions such as thermochromic or electrochromic windows alter their transmittance from dark to transparent in response to a temperature change or an external electrical control signal. Although very promising in the long-term, such smart window concepts are still rather expensive and need additional technical improvements (faster switching times, higher contrast, improved durability) in order to become attractive for large volume application.

\section{4. - Renewable energy integration - our home as a powerplant}

With an efficient building envelope, the energy demand of a building decreases by roughly $85 \%$ from $200 \mathrm{kWh} /\left(\mathrm{m}^{2}\right.$ a) for a non-insulated building to approximately $30 \mathrm{kWh} /\left(\mathrm{m}^{2} \mathrm{a}\right)$. With such a low energy demand, integration of renewable energy, mostly $\mathrm{PV}$ and solarthermal, is an economic way to cover the entire demand of a building.

Photovoltaic cells (PV) have made tremendous technological progress over the last three decades and prices have dropped accordingly, following roughly Moore's law which 


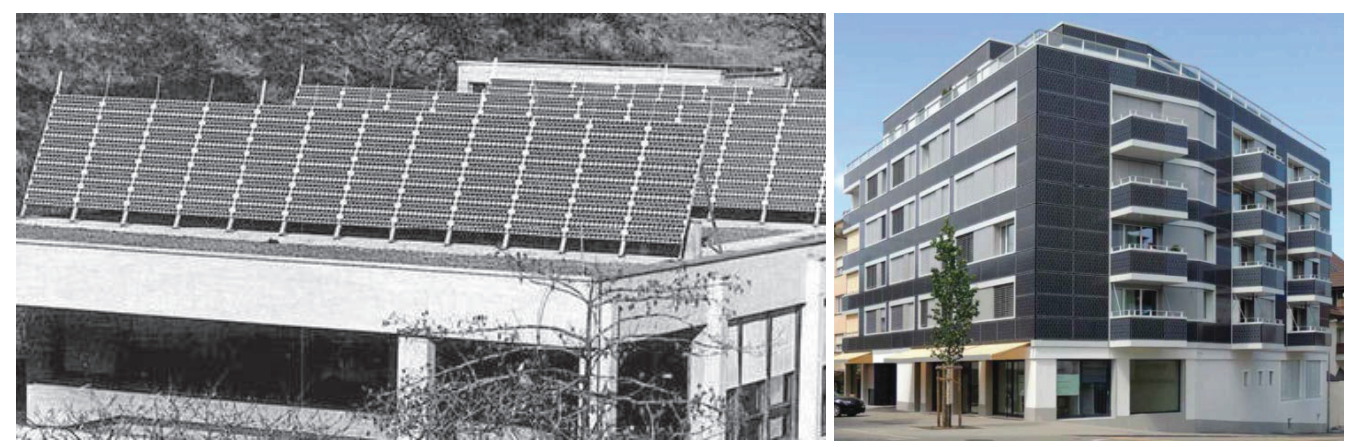

Fig. 3. - Left: oldest solar grid-connected PV system in Europe at the University of applied Sciences near Lugano, CH. Right: retrofitted plus energy building in Romanshorn, CH featuring a high-performance BiPV façade, courtesy Viriden architects.

is well known in the related silicon-based semiconductor industry. Various types of cells exist, however by far the most common type are silicon-based single junction cells with commercial products reaching $20 \%$ conversion efficiency at module prices below $0.50 \mathrm{EUR}$ per W peak power [10]. Solar thermal energy harvesting by means of thermal collectors is a parallel technology which is relatively mature in Europe but has the drawback a large amount of heat goes unused during warm summer months when demand bottoms out. Two prominent examples of a historical PV system and a building integrated photovoltaics (BIPV) retrofit are shown in fig. 3. The left example is the oldest grid connected PV system installed at the University of Applied Sciences SUPSI at Manno near Lugano.

After 30 years of continuous operation of this installation, those early silicon PV modules with a design power of $10 \mathrm{kWp}$ still have a performance $>85 \%$. The modern looking building on the right is a retrofitted 1960s multifamily home in Romanshorn, Switzerland which was converted to plus energy by means of a state of the art solar façade. Both examples clearly demonstrate that buildings represent a tremendous potential for the future integration of renewables into our energy infrastructure. Other forms of renewable energies such as wind, hydropower and biofuels typically require larger installations to operate efficiently and thus are not well-suited for building integration. With rapidly decreasing PV pricing and pending the large volume availability of electrical storage solutions such as stationary batteries or EV parks accessible through intelligent internet of things (IOT) solutions, it is expected that buildings are going to become a major producer of renewable energy in the coming decades. The main advantage of BiPV is that some of the installation cost can be synergistically compensated during the construction period of the façade and roof, whereas the rest is amortized during operation within typically $5-7$ years.

\section{5. - Energy storage and thermal energy upgrading}

The last step towards a sustainable plus energy building (see fig. 1) is the integration of suitable storage and conversion solutions. Electrical energy storage in a home should 
be designed to buffer primarily short to medium term (hours to days) energy fluctuations expected from PV systems, thus maximizing in-house utilization of the renewable production. A number of commercial battery storage solutions exist, the oldest and cheapest technology being lead acid battery technology. However this type of storage offers relatively poor long-term performance (so-called cycle stability) and as a result is not ideally suited for stationary applications. More promising concepts include Nickel metal hydride $(\mathrm{NiMH})$ and Li-ion battery technology, with the latter offering the advantage of higher power density and attractive cost perspectives (as low as $200 \mathrm{EUR} / \mathrm{kWh}$ capacity) due to massive manufacturing capacity extension as a result of a rapid acceleration of electric vehicle (EV) technologies worldwide. The disruptive EV manufacturer Tesla Motors has recently commercialized a battery storage system for home installation with an upgraded $14 \mathrm{kWh}$ capacity per module.

Other battery concepts for larger capacity station (primarily suited for district networks and as buffers for solar farms) are based on high-temperature battery systems (sodium sulfur battery, zebra battery, thermal battery). A related, promising concept is the so-called liquid-metal battery developed by MIT researchers which promises extremely high cycle stability and low system cost. Commercialization of these modules is pending until the successful long-term testing.

Electrical long-term storage is not really a practical solution to cover the production shortage and increased demand of buildings, particularly in colder areas with elevated heating demand. Thermal energy on the other hand can be stored seasonally in a much simpler manner. This means that a substantial fraction or ideally the complete heating demand during the cold season is generated in the summer months, for example from solarthermal collectors, and then gradually released into a low temperature "low exergy" floor heating system. This would allow avoiding the consumption of precious high-value energy forms such as fossil fuels or electricity to cover the heating demand. The classical approach for seasonal heat storage is to use sensible heat i.e. heat up large volumes of a medium with a high heat capacity such as water. However such a technical solution demands tremendous water storage reservoirs. Figure 4 shows a $205 \mathrm{~m}^{3}$ hot water storage reservoir needed to supply the winter heating demand for an 8-family zero-energy apartment building in Burgdorf, Switzerland realized by Jenni Energietechnik AG during the construction period. Alternative to sensible heat, latent heat storage system employ the typically much higher thermal energy density during phase transitions (melting/solidification) or chemical reactions (hydration reactions of crystalline materials) and thus require much less space for the same job. Such a system which is under development at Empa is a high ettringite content seasonal storage concrete which is dried using solar energy in the summer months and releases its stored energy upon rehydration (water addition). For a typical single-family home with a high quality envelope, it would require about $7-10 \mathrm{~m}^{3}$ of this concrete to cover the winter heating demand. A first prototype building has recently been equipped with this technology.

An even more promising class of latent-heat-based thermal systems is the thermally driven sorption heat pump technology. Such devices are able to transform low-grade $\left(<100^{\circ} \mathrm{C}\right)$ waste heat into more precious forms of thermal energy. Early concepts in the 

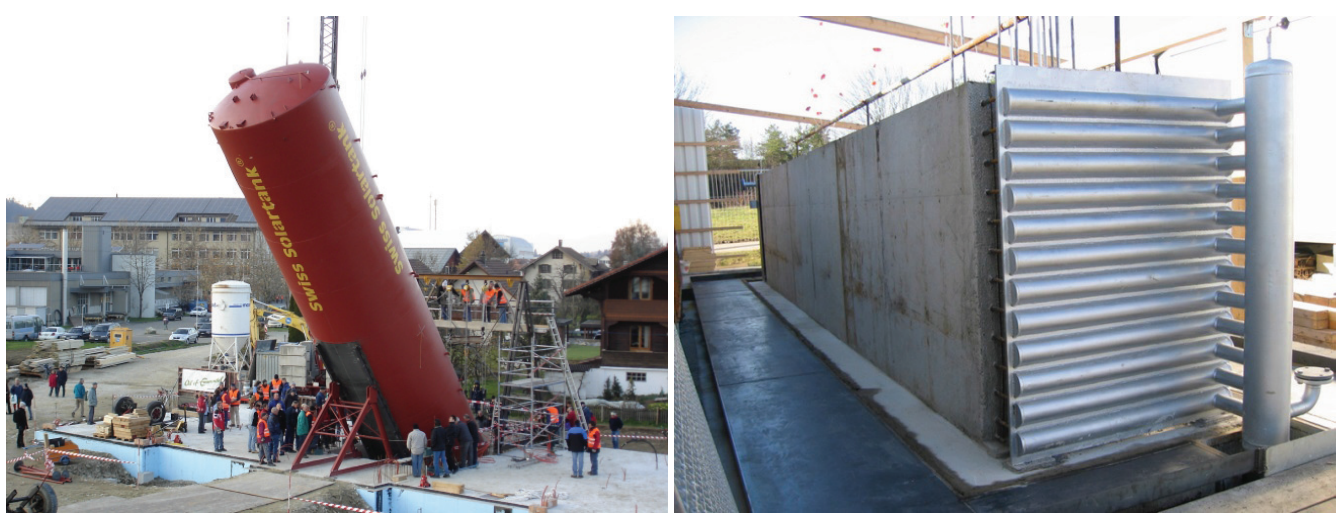

Fig. 4. - Seasonal thermal storage solutions based on sensible and latent heat, respectively.

1960s and 1970s were based on liquid sorbents with the disadvantage of high sensible heat losses (e.g. alcohol-water, ammonia). Modern systems are using the adsorption principle, which means they employ solid sorbents with a significantly lower cycled thermal mass. In comparison with a conventional heat pump in which a mechanical compressor drives the cycle, adsorption heat pumps make use of adsorption/desorption cycles of a sorbate, most often water, onto a porous solid sorbent to generate a temperature lift (or drop). One of the most promising applications from a global perspective is the transformation of waste or solarthermal energy into cooling energy, the latter often being referred to as solar cooling. Current commercial machines show already decent performance and are reliable; however improvements at both, the sorbent materials and the device and heat exchanger level can still bring significant improvements and increase competitiveness of the technology. Innovative manufacturers such as Sortech in Germany have recently developed the so-called hybrid compressor-driven/sorption heat pump machines which offer improved flexibility and exceptional performance under partial cooling loads. Figure 5 shows a schematic representation of a thermally driven heat pump at system level. Typical thermal heating and cooling coefficients of performance (COPs) are on the order of 1.5 and 0.6 , respectively. Since the overall heat pump system still requires minimal amounts of electrical energy (control electronics, valves, pumps) a second figure of merit is the respective electrical COP. These are in the order of 40 and 15 for heating and cooling, respectively. For Switzerland, the heating and cooling demand of 112 and $28 \mathrm{TWh}$, respectively could be covered to a large extent from waste and solarthermal heat sources if sorption heat pump technology were to replace compressor-driven systems [11]. Even though thermal storage and adsorption cooling are poorly known and implemented, technologies focusing on more efficient usage of waste heat such as seasonal storage and thermally driven heat pumps are expected to play an important role in energy networks. Interconnecting multiple buildings with dissimilar energy demand, production and user behavior through energy hub and energy district network systems at neighborhood, district and urban scale will be able to create excellent synergies, effectively allowing energy 


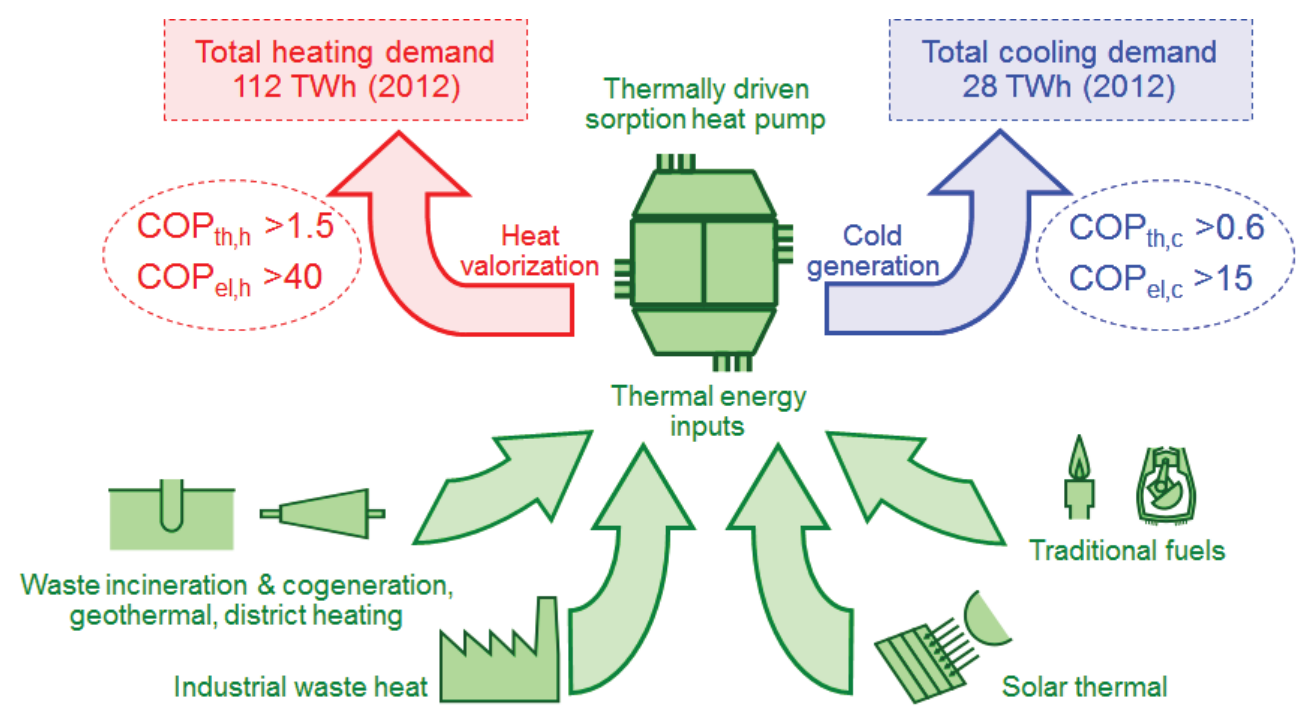

70 Energy Turnaround National Research Programme

Fig. 5. - Principle of operation and key performance figures of thermally driven solid sorption heatpumps which offer a tremendous electrical energy savings potential through the valorization of low-grade waste heat.

to be used where it is created and thus reducing conversion, transport and storage losses. This is the last and important link that connects individual buildings to create the future, energy efficient cities.

\section{6. - Need for technology demonstration and outlook}

Clearly one of the main shortcomings of the construction sector is its conservative nature and poor innovation dynamics. As a result, most home owners, investors, architects, planners and craftsmen opt for well-established conventional products. Together with certification requirements, this imposes a substantial barrier for new innovative products such as aerogel superinsulation, smart windows or thermally driven sorption heat pumps. Hence one needs to create demonstrator platforms to increase visibility of such solutions. The goal is to increase awareness and educate people about new possibilities. In this way, one can reduce time to market for sustainable technologies, systems and processes in the area of building, mobility, energy and water. NEST is a new living lab [12] at Empa in Dübendorf, Switzerland which aims to combine all state-of-the-art solutions in the building, construction and energy sector. On the monitoring side, it employs both energy fingerprinting of individual units (small apartments or office segments and direct user feedback on comfort, thus providing essential feedback for the industry during product testing and market introduction. 
In summary, the building energy topic consists of many different technological elements, none of which by themselves can solve the overall problem i.e. create low- and zero-energy buildings. As illustrated in the introductory fig. 1, economical solutions combine efficient envelopes with renewables and storage solutions. Applied research needs to fuse with innovative industrial R\&D, manufacturing and marketing teams to create the solutions of the future which we all depend on.

\section{REFERENCES}

[1] Perez-Lombard L., Ortiz J. and Pout C., Energy Build., 40 (2008) 394.

[2] Koebel M. M., Rigacci A. and Achard P., J. Sol-Gel Sci. Technol., 63 (2012) 315.

[3] Fricke J. and Borst W. L., Essentials of Energy Technology: Sources, Transport, Storage, Conservation (Wiley VCH) 2013, Chapt. 2, ISBN: 978-3-527-33416-2.

[4] Baetens R., Jelle B. P., Thue J. V. et al., Energy Build., 42 (2010) 147.

[5] Aegerter M. A., Leventis M. and Koebel M. M., Aerogels Handbook (Springer Publishing) 2011, ISBN: 978-1-4419-7477-8.

[6] https://www.basf .com/en/company/news-and-media/news-releases/2016/07/p-16248.html.

[7] http://www.fixit.ch/aerogel/?w=start\&lng=en.

[8] Ratke L., Beton Stahlbetonbau, 103 (2008) 236.

[9] Collins R. E., Turner G. M., Fischer-Cripps A. C., Tang J.-Z., Simko T. M., Dey C. J., Clugston D. A., Zhang Q.-C. and Garrison J. D., Build. Environ., 30 (1995) 459.

[10] Ito M., Lespinats S., Merten J., Malbranche P. and Kurokawa K., Prog. Photovoltaics, 24 (2016) 159.

[11] http://www.nfp70.ch/en/projects/building-settlement/heat-utilisation-withsorption-technology.

[12] http://www.empa.ch/web/nest/. 